\title{
CD204-Positive Tumor-associated Macrophages Relate to Malignant Transformation of Colorectal Adenoma
}

\author{
DAIKI TANIYAMA ${ }^{1,2,3}$, KIYOMI TANIYAMA ${ }^{1,2,3}$, KAZUYA KURAOKA ${ }^{2,3}$, \\ HIDEKI YAMAMOTO ${ }^{2,3}$, JUNICHI ZAITSU ${ }^{2,3}$, AKIHISA SAITO ${ }^{2,3}$, \\ NAOYA SAKAMOTO ${ }^{1}$, KAZUHIRO SENTANI $^{1}$, NAOHIDE OUE ${ }^{1}$ and WATARU YASUI ${ }^{1}$ \\ ${ }^{1}$ Department of Molecular Pathology, Graduate School of Biomedical and \\ Health Sciences, Hiroshima University, Hiroshima, Japan; \\ ${ }^{2}$ Institute for Clinical Research, National Hospital Organization Kure \\ Medical Center and Chugoku Cancer Center, Kure, Japan; \\ ${ }^{3}$ Department of Diagnostic Pathology, National Hospital Organization, \\ Kure Medical Center and Chugoku Cancer Center, Kure, Japan
}

\begin{abstract}
Background/Aim: Colorectal adenoma is well known as a precursor lesion of colorectal adenocarcinoma $(A D C)$. We recently reported the significance of CD204 (+) tumor-associated macrophages (TAMs), a vital component of the tumor microenvironment, in the carcinoma development of gastric adenoma. The aim of the present study was to clarify the roles of TAM in the malignant transformation of colorectal adenoma. Materials and Methods: We immunohistochemically assessed the TAM number in 88 tubular or tubulovillous adenomas that were classified into L (low-grade adenomas) or $H$ (high-grade adenomas). Results: Larger adenoma size, higher frequency of villous structure, loss of proliferation polarity, p53 expression, larger TAM numbers and larger microvessel density (MVD) were detected in Group H than in Group L adenomas. Positive relations were observed between $T A M$ and MVD, proliferation polarity and the expression of p53. Conclusion: CD204 (+) TAM is a novel component in the malignant transformation of colorectal adenoma.
\end{abstract}

Colorectal cancer (CRC) is one of the leading causes of cancer-associated death worldwide (1). Many CRCs arise from adenomatous polyps through a machinery that we call the "adenoma-carcinoma sequence" (2). Larger size, villous structure, and high-grade morphology are known to represent a higher frequency of potential as precursors of CRC (3). In

Correspondence to: Kiyomi Taniyama, MD, Ph.D., Honorary President, National Hospital Organization Kure Medical Center and Chugoku Cancer Center, 3-1 Aoyama-cho, Kure 737-0023, Japan. Tel: +81 823223111, Fax: +81 823210478, e-mail: taniyamaf@go2.enjoy.ne.jp

Key Words: Colorectal adenoma, tumor-associated macrophages, CD204, adenoma-carcinoma sequence. recent studies, it is obvious that $\mathrm{CRC}$ arose from adenomas with an accumulation of mutations in tumor suppressor genes and oncogenes (4).

Accumulating evidence supports the idea that the development and progression of tumor tissue is greatly influenced by the tumor microenvironment (5). Tumor cells and stromal cells, such as lymphocytes, fibroblasts, endothelial cells and macrophages are believed to intermingle with each other in a "tumor microenvironment". In particular, cancer-associated fibroblasts and tumor associated macrophages (TAMs) infiltrate tumor tissue and are believed to be one of the crucial components of the tumor microenvironment. TAMs are actually known to possess an angiogenic ability in the tumor microenvironment, which has been supported by the positive correlation between TAMs and MVD in several malignant tumors $(6,7)$. Several studies have reported significant correlations between TAM and poor outcomes in patients with many types of malignancies (8). According to the reports, TAM had the ability to polarize into M2 macrophages upon exposure to M2 macrophage-differentiation factors produced by the tumor microenvironment (5). CD204 is a class A scavenger receptor that is highly expressed in M2-polarized macrophages and CD204 (+) TAMs that are related to tumor progression in several types of cancers, such as lung cancer, pancreatic cancer, ovarian tumor and glioma $(6,9-12)$. These previous studies mainly focused on the role of TAMs in further progression of the advanced tumor. To the best of our knowledge, research concerning the role of TAM in precancerous lesions is quite limited and our previous report on gastric adenoma (13) seems to be the only one so far. Moreover, the role of CD204 (+) TAMs in the initiation of colorectal ADC from a conventional adenoma has not yet been elucidated.

Herein, we used immunohistochemistry (IHC) against colorectal adenomas, including low-grade, high-grade and 
adenomas that harbor intramucosal adenocarcinomas to investigate the possible functional roles of CD204 (+) TAMs in the progression of colorectal adenoma to carcinoma.

\section{Materials and Methods}

Patients and tumors. Among polyps removed via endoscopic mucosal resection (EMR) at the National Hospital Organization, Kure Medical Center and Chugoku Cancer Center, Japan between 2014 and 2017, 88 tubular or tubulovillous polypoid adenomas were randomly selected and enrolled in the present study. Superficial depressed-type adenomas were not included. These adenomas were grouped into L (48 low-grade adenomas: mild atypia, 24; moderate atypia, 24) or $\mathrm{H}$ (40 high-grade adenomas: severe atypia, 21; intramucosal adenocarcinoma in adenoma, 19). Normal mucosa was obtained from the L group samples that did not contain areas of adenoma or erosion and was examined as the control tissue. Clinicopathological features such as gender, age, size, location, and the presence of villous structure in the adenomas were investigated retrospectively from endoscopic and pathological records to assess the difference between the two groups. Inaccuracy in size assessment of the polyp removed at colonoscopy using conventional millimeter ruler has been reported in previous studies $(14,15)$. In this study, the size of all adenomas was measured on digitalized image of hematoxylin and eosin stained slides using a measurement tool in VS800 Whole Slide Imaging system (OLYMPUS, Tokyo, Japan). All patient samples were obtained with consent, and this study was approved by the Institutional Review Board of National Hospital Organization Kure Medical Center and Chugoku Cancer Center (24-Oct-2017, approval No. IEC201504) and conformed to the ethical standards of the Declaration of Helsinki.

Evaluation of pathological features. EMR specimens were fixed in a $10 \%$ formalin briefly after the tissue was resected and embedded in paraffin. Sections that were 3-4 $\mu \mathrm{m}$ thick were stained using hematoxylin and eosin in a routine procedure. Original diagnoses were made by two pathologists that included at least one boardcertified surgical pathologist by the Japanese Society of Pathology with expertise in gastrointestinal cancer diagnosis (KT or KK). For the present study, each EMR specimen was reviewed by another board-certified pathologist (NS) who had no information about the original diagnosis. Pathological diagnoses were based on the 9th edition of the Japanese Classification of Colorectal Carcinoma (16) and the 4th edition of the WHO Classification of Tumors of the Digestive System (17).

Antibodies and immunohistochemistry. Sequential 3-4 $\mu$ m-thick slides were used for the IHC study as reported previously (18). The antibodies for Ki-67 (clone MIB-1, monoclonal, diluted 1:50; DAKO, Glostrup, Denmark), p53 (clone DO-7, monoclonal, diluted 1:50; DAKO), CD34 (clone QBEnd-10, monoclonal, diluted 1:50; DAKO), and CD204 (clone SRA-E5, monoclonal, diluted 1:200; Transgenic, Tokyo, Japan) were used as the primary antibodies to detect the corresponding protein expression. IHC for CD204 was performed using an Autostainer (DAKO) according to the manufacturer's instructions. IHC for Ki-67, p53, and CD34 were performed using a VENTANA BenchMark XT automated staining instrument (Ventana), according to the manufacturer's instructions (13).
Table I. Comparison of clinical and histopathologic findings of two groups $(n=88)$.

\begin{tabular}{lccc}
\hline Patient characteristics & $\mathrm{L}(\mathrm{n}=48)$ & $\mathrm{H}(\mathrm{n}=40)$ & $p$-Value \\
\hline Gender (\%) & $32(66.7)$ & $33(82.5)$ & $\mathrm{NS}$ \\
Male & $16(33.3)$ & $7(17.5)$ & \\
Female & $72.1 \pm 7.1$ & $70.3 \pm 7.7$ & $\mathrm{NS}$ \\
Age (year), mean \pm SD & & & \\
Location (\%) & $15(31.3)$ & $9(22.5)$ & \\
Ascending & $13(27.1)$ & $5(12.5)$ & \\
Transverse & $2(4.2)$ & $6(5.0)$ & $\mathrm{NS}$ \\
Descending & $14(29.2)$ & $16(40.0)$ & \\
Sigmoid & $4(8.3)$ & $4(10.0)$ & \\
Rectum & $15(40.5)$ & $9(25.0)$ & $\mathrm{NS}$ \\
Right & $22(59.5)$ & $27(75.0)$ & \\
Left & & & \\
Adenoma size $(\mathrm{mm})$ & $3.2 \pm 1.5$ & $6.5 \pm 3.2$ & $<0.001$ \\
mean \pm SD & $2(3.8)$ & $8(18.6)$ & 0.020 \\
Villous structure $(\%)$ & $46(96.2)$ & $32(81.4)$ & \\
Present & & \\
Absent & &
\end{tabular}

Group L: 24 cases of mild atypia and 24 cases of moderate atypia; Group H: 21 cases of severe atypia and 19 cases of adenoma that contain intramucosal adenocarcinoma; NS: not significant.

Table II. Comparison of immunohistochemical findings of two groups $(n=88)$.

\begin{tabular}{lcccc}
\hline & $\mathrm{NM}(\mathrm{n}=20)$ & $\mathrm{L}(\mathrm{n}=48)$ & $\mathrm{H}(\mathrm{n}=40)$ & $p$-Value \\
\hline $\begin{array}{l}\text { Number of TAM } \\
\text { Mean } \pm \text { SD }\end{array}$ & $38.2 \pm 11.9$ & $70.0 \pm 33.3$ & $115.3 \pm 63.1$ & $<0.001$ \\
$\begin{array}{l}\text { Number of microvessel } \\
\text { Mean } \pm \text { SD }\end{array}$ & $25.2 \pm 2.8$ & $32.0 \pm 10.6$ & $55.0 \pm 14.9$ & $<0.001$ \\
Proliferative zone (\%) & & & & \\
$\quad$ Bottom-up & $20(100)$ & $2(6.1)$ & $0(0)$ & \\
Top-down & $0(0)$ & $18(54.5)$ & $4(31.4)$ & $<0.001$ \\
Diffuse & $0(0)$ & $13(39.4)$ & $33(65.7)$ & \\
p53 (\%) & & & & \\
$\quad$ Negative & $20(100)$ & $46(97.9)$ & $26(66.7)$ & $<0.001$ \\
Positive & $0(0)$ & $1(2.1)$ & $13(33.3)$ & \\
\hline
\end{tabular}

NM: Normal mucosa; TAM: tumor associated macrophage.

Quantitative analysis of macrophage and microvessel density. After immunohistochemical staining, the results were stored digitally after examination by virtual microscopy with a NanoZoomer 2.0-HT (Hamamatsu Photonics, Hamamatsu, Japan). TAMs were identified as CD204 positive cells with oval to round nuclei showing membranous/cytoplasmic staining (13). TAM numbers were counted in three hot spots. Each spot that was $0.05 \mathrm{~mm}^{2}$ in size was selected by the above-mentioned two pathologists independently and a consensus interpretation was made when there were discordant results. Area was measured using the Genie/Aperio software package, which visualized the CD204-positive area as yellow, orange or red-colored areas and positive cells were calculated automatically. Blue cells were regarded as negative. 
Table III. Univariate and multivariate analysis of high-grade adenoma.

\begin{tabular}{|c|c|c|c|c|c|c|}
\hline & \multicolumn{3}{|c|}{ Univariate analysis } & \multicolumn{3}{|c|}{ Multivariate analysis } \\
\hline & OR & $95 \% \mathrm{CI}$ & $p$-Value & OR & $95 \%$ CI & $p$-Value \\
\hline \multicolumn{7}{|l|}{ Tumor size } \\
\hline $5 \mathrm{~mm}$ & 22.85 & $6.75-77.29$ & $<0.001$ & 3.22 & $0.50-23.71$ & NS \\
\hline$<5 \mathrm{~mm}$ & 1.00 & & & 1.00 & & \\
\hline \multicolumn{7}{|l|}{ Villous structure } \\
\hline present & 5.75 & $1.15-28.88$ & 0.020 & $8.7 \times 10^{6}$ & $0.57-\infty$ & NS \\
\hline absent & 1.00 & & & 1.00 & & \\
\hline \multicolumn{7}{|l|}{ Proliferation polarity } \\
\hline Diffuse & 12.69 & $3.63-44.33$ & $<0.001$ & 11.95 & $2.17-102.75$ & 0.003 \\
\hline Bottom-up or Top-Down & 1.00 & & & 1.00 & & \\
\hline \multicolumn{7}{|l|}{ Number of TAM } \\
\hline High ( $\geq$ mean $)$ & 4.05 & $1.66-9.88$ & 0.002 & 1.29 & $0.25-8.24$ & NS \\
\hline Low $(<$ mean $)$ & 1.00 & & & 1.00 & & \\
\hline \multicolumn{7}{|l|}{ Number of microvessel } \\
\hline High $(\geq$ mean $)$ & 17.33 & $6.00-50.08$ & $<0.001$ & 23.49 & $4.71-187.95$ & $<0.001$ \\
\hline Low $(<$ mean $)$ & 1.00 & & & 1.00 & & \\
\hline
\end{tabular}

$\mathrm{N}=70, \mathrm{R}^{2}=0.55$, Model $p$-value: $p<0.0001$. NS: Not significant; TAM: tumor-associated macrophage.

Microvessels that had an entire circumference of CD34 (+) endothelial cells were counted. Each spot of $0.05 \mathrm{~mm}^{2}$ in size was selected and the area was measured using the above-mentioned software with no relation to these spots for CD204 counts.

Other immunohistochemical analysis. IHC for Ki-67 was conducted to elucidate the proliferative activity of adenoma. Since there was inaccuracy in counting the number of nuclei or cells due to overlapping in most of the cases, we assessed the distribution of a proliferative zone. The proliferative zone was grouped into three categories: bottom-up, top-down or diffuse according to the method described by Watanabe et al. (19). Adenomas that had Ki-67 positive cells mainly in the lower crypt were defined as bottom-up. Adenomas that had Ki-67 positive cells in surface epithelium were defined as top-down. Adenomas that showed strong expression throughout the crypts were defined as diffuse. Since a previous study showed that a TAM number was related to p53 expression in CRC (20), we also validated p53 expression in the present study. Only unequivocal nuclear staining was considered positive and was graded as 1 to 3 according to the percentage of stained tumor cells (21). The results for p53 expression were: 0 , almost no positive cells; $1,5-25 \% ; 2,25-50 \%$; and 3 , over $50 \%$ of tumor cells showed immunoreactivity. Grades 2 and 3 were regarded as p53 positive adenoma.

Statistical analysis. Associations between clinicopathological and immunohistochemical results for each stain were analyzed by $\chi^{2}$ test. Univariate and multivariate analysis for differences in two groups were performed using a logistic regression analysis model. Significant differences detected by multivariate analysis were chosen by the stepwise method. The odds ratio (OR) and 95\% confidence interval (CI) were estimated from the logistic regression analysis. Statistical analyses were conducted with JMP v. 9 (SAS Institute, Cary, NC). A $p$-value of $<0.05$ was considered statistically significant.

\section{Results}

Clinicopathological data. Clinicopathological and histological features of both groups are shown in Table I and representative cases of tubular adenoma are shown in Figure 1. There was no significant difference in sex, age and location. The mean adenoma sizes of group $\mathrm{L}$ adenomas and group $\mathrm{H}$ adenomas were $3.2 \mathrm{~mm}$ and $6.5 \mathrm{~mm}$, respectively, with a significant difference $(p<0.001)$. Villous structure was found in two (3.8\%) cases of group L adenomas and in eight cases $(18.6 \%)$ of group $\mathrm{H}$ adenomas with a statistical difference $(p=0.020)$.

CD204 (+) TAM number in colorectal adenomas. CD204 (+) TAMs in tumor stroma were measured in order to validate the characteristics of TAM in colorectal adenomas (Figure $2 \mathrm{~A}$ and B). Mean CD204 (+) TAM numbers in normal mucosa, group L and $\mathrm{H}$ adenomas were 38.2, 70.0 and 115.3, respectively $(p<0.001$, Table II). In group $\mathrm{H}$ adenomas, mean TAM number per $1 \mu \mathrm{m}^{2}$ was also significantly larger than that of group L adenomas (data not shown). A positive correlation was detected between TAM number and adenoma size $(p<0.0001 ; \mathrm{r}=0.59$, data not shown). These data indicated that CD204 (+) TAM may be involved in the progression of colorectal adenoma.

Correlation between CD204 (+) TAM with MVD and other immunohistochemical results. To further elucidate the role of CD204 (+) TAM in adenoma we analyzed the correlation with MVD (Figure 2C and D), proliferation polarity and p53 expression (Figure 3). Since previous studies showed that CD204 (+) TAMs promote vascularization, we examined the 

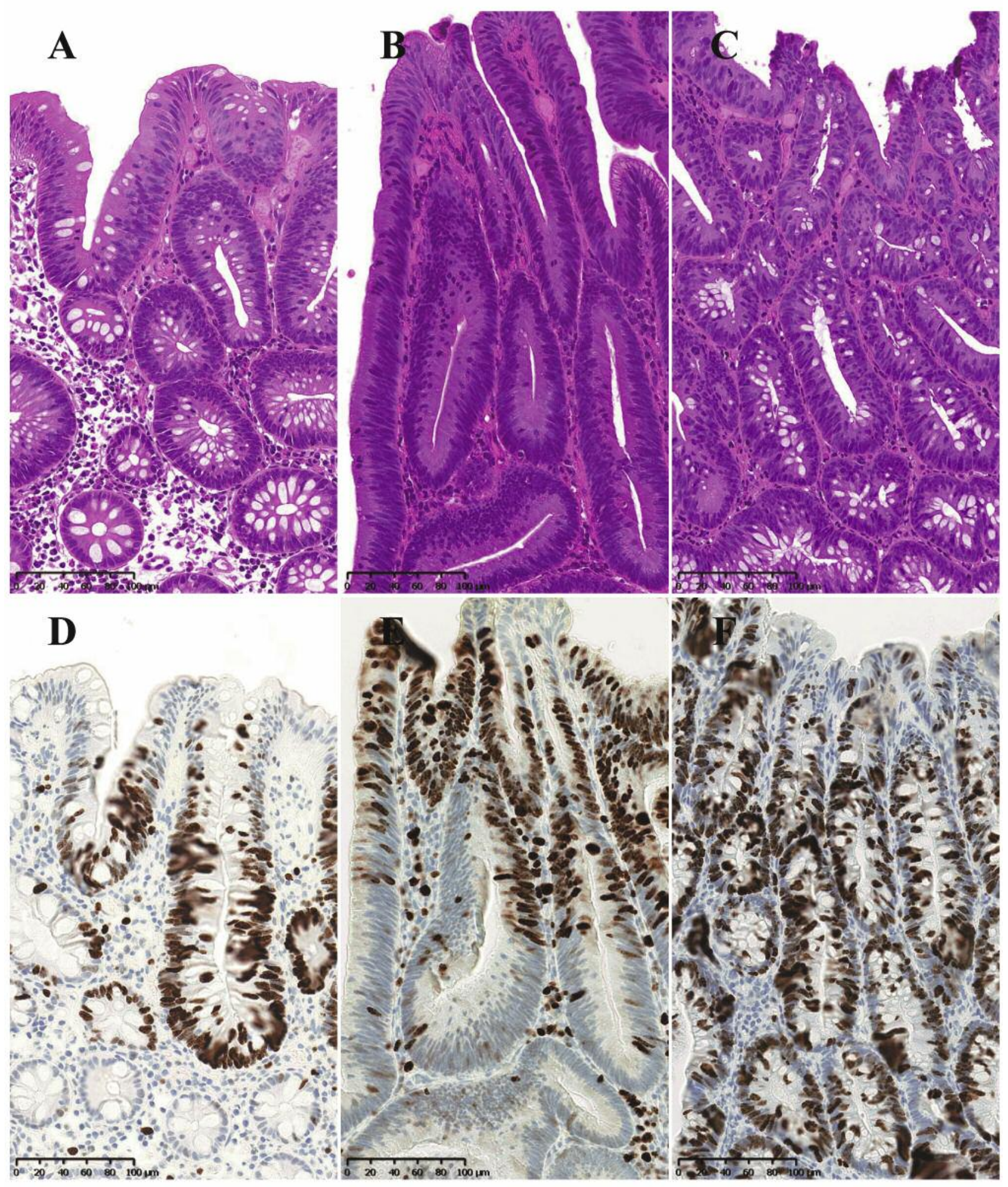

Figure 1. Morphological features of colorectal adenomas included in this study and IHC of Ki-67 and measurement of proliferation polarity (original magnification $\times 200$ ). (A, D) Group L. Tubular adenoma with mild atypia showing bottom-up type proliferation polarity. (B, E) Group L. Tubular adenoma with moderate atypia showing top-down type proliferation polarity. $(C, F)$ Group $H$. Tubular adenoma with severe atypia showing diffuse type proliferation polarity. 

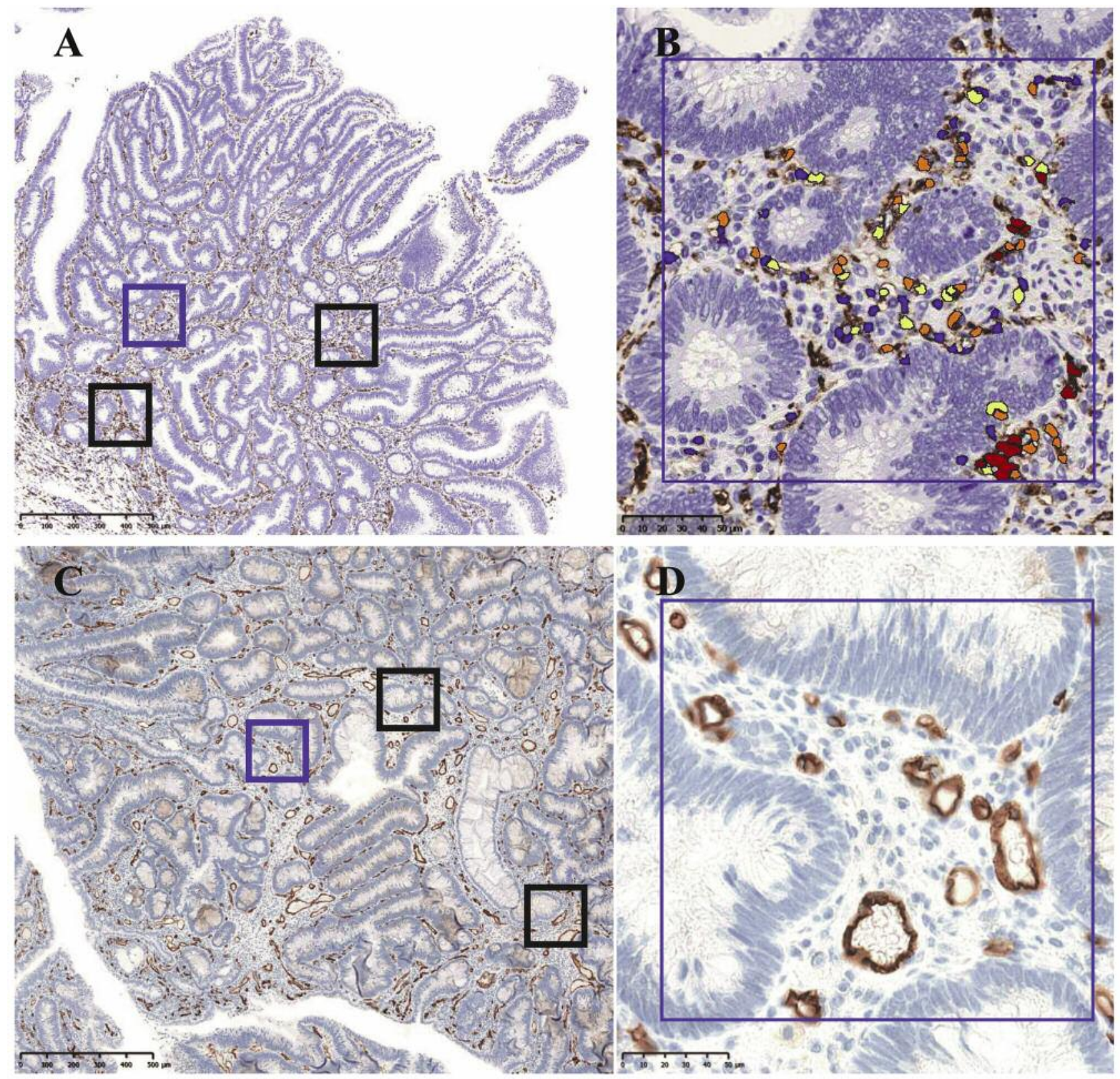

Figure 2. IHC for CD204 expression in TAMs $(A, B)$ and CD34 antibody for microvessels $(C, D)$. (A) Three hot spots, each spot $0.05 \mathrm{~mm}^{2}$ in size, were selected (original magnification $\times 50$ ). (B) Higher magnification of blue boxed area of (A). Tubular adenoma with severe atypia that have many TAMs (original magnification $\times 400$ ). (C) Three hot spots, each spot $0.05 \mathrm{~mm}^{2}$ in size, were selected with no relation to these spots for CD204 counts (original magnification $\times 50$ ). (D) Higher magnification of blue boxed area of $(C)$. Tubular adenoma with severe atypia that has high MVD (original magnification $\times 400$ ).

number of MVD. Numbers of MVD in normal mucosa, group $\mathrm{L}$ and group $\mathrm{H}$ adenoma were 25.2, 32.0 and 55.0, respectively, with a significant difference $(p<0.001$, Table II). Significant differences were also found between normal and group $\mathrm{L}$, normal and group $\mathrm{H}$ and also group $\mathrm{L}$ and group $\mathrm{H}$ ( $p=0.044, p<0.001$ and $p<0.001$, data not shown). Notably, the number of CD204 (+) TAM was significantly correlated with MVD $(p<0.001 ; r=0.484$, Figure 4A), suggesting the tumorigenic role of CD204 (+) TAM in the progression of an adenoma to CRC via promotion of angiogenesis.

Recent studies demonstrated a correlation of the number of TAMs with the Ki-67 labeling index of tumor cells in breast cancer and cerebral glioma $(22,23)$. Thus, we examined the correlation between CD204 (+) TAM number 

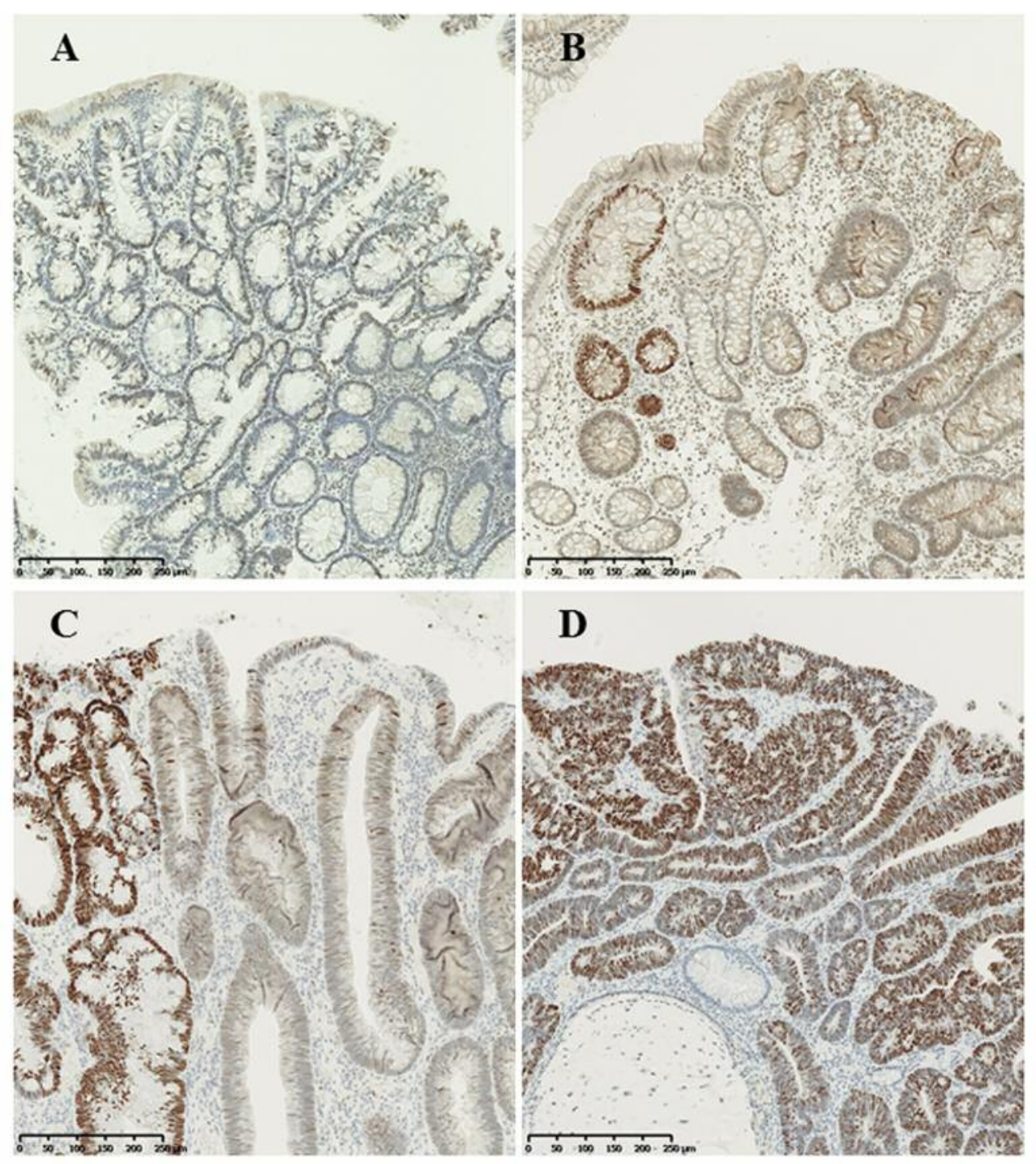

Figure 3. IHC for p53. (A) Adenoma with mild atypia. Staining grade was 0 and regarded as negative. (B) Adenoma with mild atypia. Staining grade was 1 and regarded as negative. (C) Intramucosal adenocarcinoma. Staining grade was 2 and regarded as positive. (D) Intramucosal adenocarcinoma. Staining grade was 3 and regarded as positive.

and proliferation polarity of colorectal tumors. A representative picture of proliferative zones is shown in Figure 1. All normal glands in mucosa showed a bottom-up type. The top-down type was frequently detected in group $\mathrm{L}$ and the diffuse type was frequent in group $\mathrm{H}(p<0.001$, Table II). The CD204 (+) TAM number was significantly larger in the diffuse type, which indicated that the loss of proliferation polarity occurred frequently in group $\mathrm{H}$ adenomas $(p<0.001$, Figure 4B).

p53-up-regulation in colorectal adenomas. The glands of normal mucosa were completely negative for $\mathrm{p} 53$ expression. In group $\mathrm{L}$ and $\mathrm{H}$ the percent of tumors negative for $\mathrm{p} 53$ expression were $97,9 \%(46)$ and $66.7 \%$ (26), respectively (Table II). The difference was statistically significant $(p<0.001)$. One and 13 tumors were positive in group $\mathrm{L}$ and $\mathrm{H}$ adenomas, respectively, (Table II). The CD204 (+) TAM number was larger in $\mathrm{p} 53$ positive adenomas $(p=0.033$, Figure $4 C)$. These data confirmed a good correlation between CD204 (+) TAM number and p53 expression of tumor cells in colorectal adenomas.

A multivariate analysis was also performed to assess the significances detected by univariate analysis. Among tumor size, villous structure, proliferation polarity, CD204 (+) TAM number and MVD, only proliferation polarity and MVD were assessed as significant (Table III). 


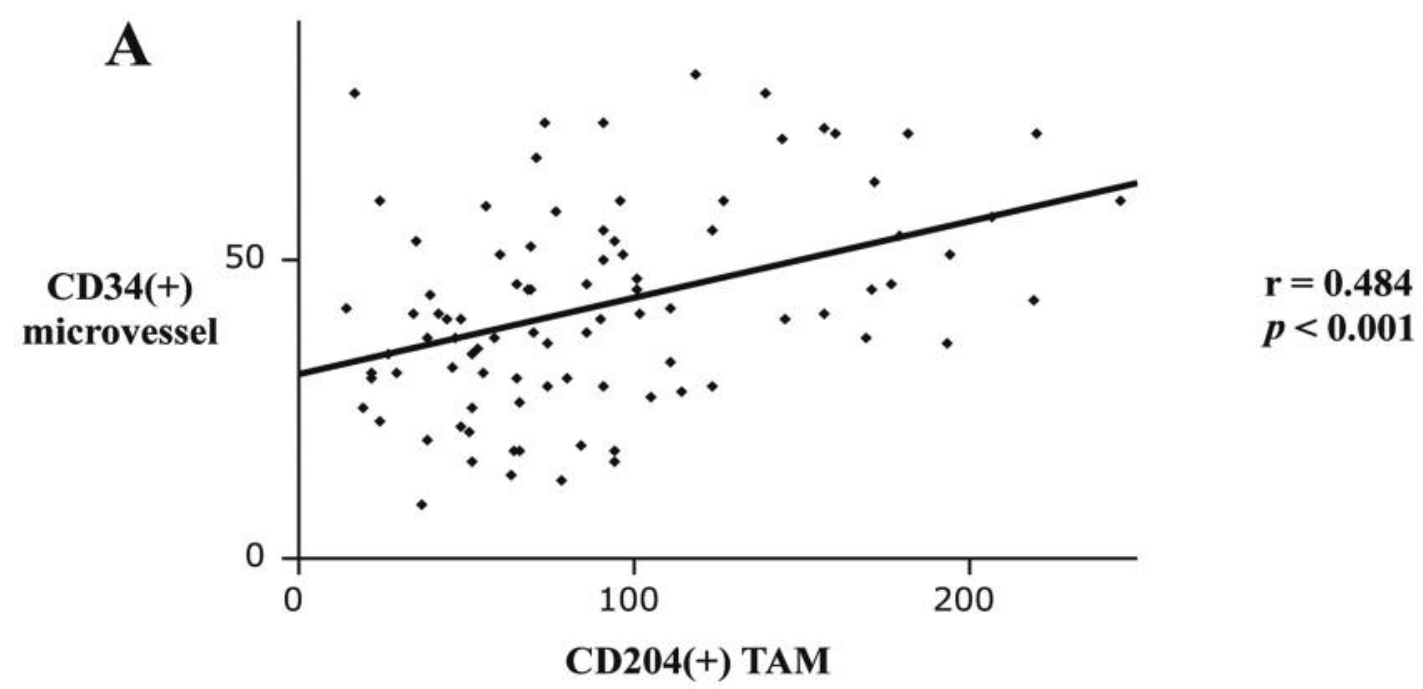

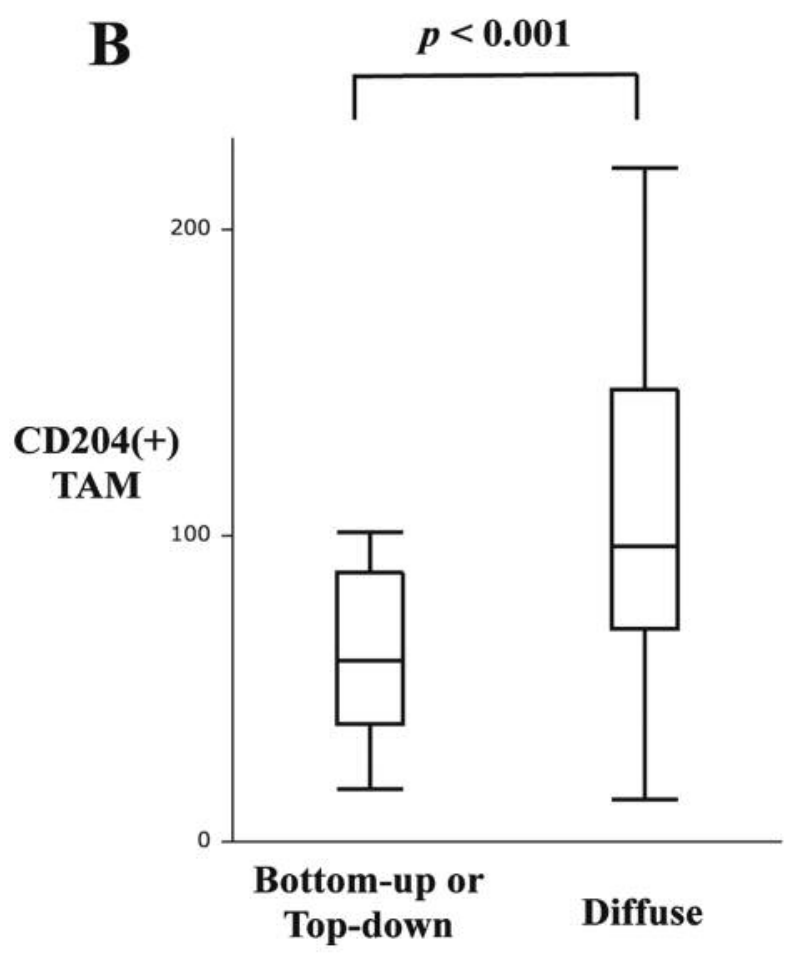

Proliferative zone

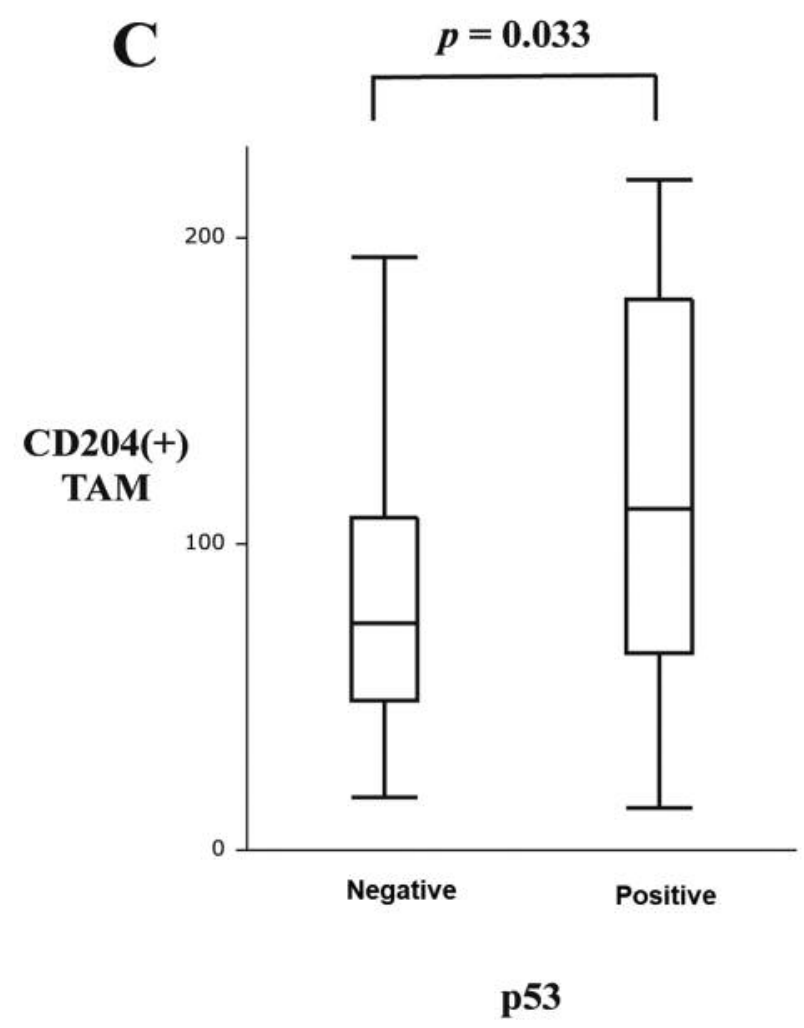

Figure 4. Comparative analysis of the expression of CD204 (+) TAM in the stroma. (A) Correlations between the number of CD204 (+) TAMs and the MVD $(A)$, proliferation polarity $(B)$ and 553 expression $(C)$ in the stroma.

\section{Discussion}

The CD204 (+) TAM number was not found to be significantly different between group $\mathrm{L}$ and $\mathrm{H}$ adenomas by a multivariate analysis. This number was demonstrated to be an independent risk factor for developing gastric adenocarcinoma of an intestinal type thru gastric tubular adenoma (13). This suggests a different role for the CD204 (+) TAM in the adenoma-carcinoma sequence in colorectum compared with that in stomach. However, the CD204 (+) 
TAM number was significantly larger in $\mathrm{H}$ adenomas than in others, and was correlated with proliferation polarity, p53 expression of tumor cells, and MVD in the colorectal adenoma. Therefore, the CD204 (+) TAM should play a significant role in carcinoma development from a colorectal adenoma. Hirayama et al. (6) reported that CD204 (+) TAMs were correlated with the MVD in lung squamous cell carcinoma. Although several studies have reported a significant correlation between TAM number and malignant tumor biology (8), to the best of our knowledge there are no reports examining the functional role of TAM in a precancerous lesion. Colorectal adenomas larger than $6 \mathrm{~mm}$ in size are objects of excisional biopsy and a long duration follow-up has never been done for them. The absence of follow-up data in the present study may account for the reduced level of statistical significance of the association of CD204 (+) TAM number with colorectal adenomas compared with that in gastric adenomas in which long-term follow-up was incorporated. In the latter case, we found that the increase in CD204(+) TAM number preceded the morphological changes of adenoma cells (13).

In CRC, the role of TAM remains unclear. Many studies reported that a higher number of CD68 (+) TAMs in the invasive front was related to favorable outcome $(24,25)$, while other reports indicated that intratumoral CD68 (+) TAM counts were related with depth of invasion, lymph node metastasis, and staging of colorectal cancer (26). In the present study, we used auto-stainers for IHC and autocounting for the CD204 (+) TAM number. The results are objective and reproducible (27). CD68 is a marker for panmacrophages and CD204 is an M2 marker (23). Macrophages in a tumor microenvironment show various phenotypes $(28,29)$. Our study demonstrated the significance of CD204 (+) TAM in adenoma progression as a novel finding in the adenoma-carcinoma sequence in the colorectum.

In conclusion, a CD204 (+) TAM number is significantly related to MVD in stroma and the loss of proliferation polarity, and p53 expression of adenoma cells in colorectum. Further studies should be carried out to clarify TAM function in the colorectal adenoma-carcinoma sequence.

\section{Conflicts of Interest}

The Authors declare no conflicts of interest in association with the present study.

\section{Authors' Contributions}

DT, KK, HY, NS, KS, NO, WY and KT designed the present study. DT, JZ, AS, HY, NS, KK and KT performed experiments and acquired data. DT, JZ, AS, HY and KK provided patients' clinical information. DT, KK, HY, NS, KS, NO, WY and KT interpreted the results. DT and NS drafted the manuscript. WY and KT edited it.

\section{Acknowledgements}

The Authors thank Miyuki Kiriki, Arisa Kan, Hiroki Fuzisawa, Naoko Yasumura, Miho Yoshida and Yoko Kodama for their excellent technical assistance and organization of this research.

\section{References}

1 Fitzmaurice C, Dicker D, Pain A, Hamavid H, Moradi-Lakeh M, MacIntyre MF, Allen C, Hansen G, Woodbrook R, Wolfe C, Hamadeh RR, Moore A, Werdecker A, Gessner BD, Te Ao B, McMahon B, Karimkhani C, Yu C, Cooke GS, Schwebel DC, Carpenter DO, Pereira DM, Nash D, Kazi DS, De Leo D, Plass D, Ukwaja KN, Thurston GD, Yun Jin K, Simard EP, Mills E, Park EK, Catala-Lopez F, deVeber G, Gotay C, Khan G, Hosgood HD, 3rd, Santos IS, Leasher JL, Singh J, Leigh J, Jonas JB, Sanabria J, Beardsley J, Jacobsen KH, Takahashi K, Franklin RC, Ronfani L, Montico M, Naldi L, Tonelli M, Geleijnse J, Petzold M, Shrime MG, Younis M, Yonemoto N, Breitborde N, Yip P, Pourmalek F, Lotufo PA, Esteghamati A, Hankey GJ, Ali R, Lunevicius R, Malekzadeh R, Dellavalle R, Weintraub R, Lucas R, Hay R, Rojas-Rueda D, Westerman R, Sepanlou SG, Nolte S, Patten S, Weichenthal S, Abera SF, Fereshtehnejad SM, Shiue I, Driscoll T, Vasankari T, Alsharif U, Rahimi-Movaghar V, Vlassov VV, Marcenes WS, Mekonnen W, Melaku YA, Yano Y, Artaman A, Campos I, MacLachlan J, Mueller U, Kim D, Trillini M, Eshrati B, Williams HC, Shibuya K, Dandona R, Murthy K, Cowie B, Amare AT, Antonio CA, Castaneda-Orjuela C, van Gool CH, Violante F, Oh IH, Deribe K, Soreide K, Knibbs L, Kereselidze M, Green M, Cardenas R, Roy N, Tillmann T, Li Y, Krueger H, Monasta L, Dey S, Sheikhbahaei S, Hafezi-Nejad N, Kumar GA, Sreeramareddy CT, Dandona L, Wang H, Vollset SE, Mokdad A, Salomon JA, Lozano R, Vos T, Forouzanfar M, Lopez A, Murray C and Naghavi M: The global burden of cancer 2013. JAMA Oncol 1(4): 505-527, 2015. PMID: 26181261. DOI: 10.1001/jamaoncol.2015.0735

2 Baker AM, Graham TA, Elia G, Wright NA and Rodriguez-Justo M: Characterization of lgr5 stem cells in colorectal adenomas and carcinomas. Sci Rep 5(8654), 2015. PMID: 25728748. DOI: 10.1038/srep08654

3 Heitman SJ, Ronksley PE, Hilsden RJ, Manns BJ, Rostom A and Hemmelgarn BR: Prevalence of adenomas and colorectal cancer in average risk individuals: A systematic review and metaanalysis. Clin Gastroenterol Hepatol 7(12): 1272-1278, 2009. PMID: 19523536. DOI: 10.1016/j.cgh.2009.05.032

4 Carethers JM and Jung BH: Genetics and genetic biomarkers in sporadic colorectal cancer. Gastroenterology 149(5): 11771190.e1173, 2015. PMID: 26216840. DOI: 10.1053/j.gastro. 2015.06.047

5 Jinushi M and Komohara Y: Tumor-associated macrophages as an emerging target against tumors: Creating a new path from bench to bedside. Biochim Biophys Acta 1855(2): 123-130, 2015. PMID: 25595840. DOI: 10.1016/j.bbcan.2015.01.002

6 Hirayama S, Ishii G, Nagai K, Ono S, Kojima M, Yamauchi C, Aokage K, Hishida T, Yoshida J, Suzuki K and Ochiai A: Prognostic impact of cd204-positive macrophages in lung squamous cell carcinoma: Possible contribution of cd204positive macrophages to the tumor-promoting microenvironment. J Thorac Oncol 7(12): 1790-1797, 2012. PMID: 23154550. DOI: 10.1097/JTO.0b013e3182745968 
7 Kawahara A, Hattori S, Akiba J, Nakashima K, Taira T, Watari K, Hosoi F, Uba M, Basaki Y, Koufuji K, Shirouzu K, Akiyama S, Kuwano M, Kage M and Ono M: Infiltration of thymidine phosphorylase-positive macrophages is closely associated with tumor angiogenesis and survival in intestinal type gastric cancer. Oncol Rep 24(2): 405-415, 2010. PMID: 20596627.

8 Takeya $\mathrm{M}$ and Komohara Y: Role of tumor-associated macrophages in human malignancies: Friend or foe? Pathol Int 66(9): 491-505, 2016. PMID: 27444136. DOI: 10.1111/pin. 12440

9 Bak SP, Walters JJ, Takeya M, Conejo-Garcia JR and Berwin BL: Scavenger receptor-a-targeted leukocyte depletion inhibits peritoneal ovarian tumor progression. Cancer Res 67(10): 4783 4789, 2007. PMID: 17510407. DOI: 10.1158/0008-5472.CAN$06-4410$

10 Komohara Y, Ohnishi K, Kuratsu J and Takeya M: Possible involvement of the $\mathrm{m} 2$ anti-inflammatory macrophage phenotype in growth of human gliomas. J Pathol 216(1): 15-24, 2008. PMID: 18553315. DOI: 10.1002/path.2370

11 Kurahara H, Shinchi H, Mataki Y, Maemura K, Noma H, Kubo F, Sakoda M, Ueno S, Natsugoe S and Takao S: Significance of $\mathrm{m} 2$-polarized tumor-associated macrophage in pancreatic cancer. J Surg Res 167(2): e211-219, 2011. PMID: 19765725. DOI: 10.1016/j.jss.2009.05.026

12 Ohtaki Y, Ishii G, Nagai K, Ashimine S, Kuwata T, Hishida T, Nishimura M, Yoshida J, Takeyoshi I and Ochiai A: Stromal macrophage expressing cd204 is associated with tumor aggressiveness in lung adenocarcinoma. J Thorac Oncol 5(10): 1507-1515, 2010. PMID: 20802348. DOI: 10.1097/JTO.0b01 $3 \mathrm{e} 3181 \mathrm{eba} 692$

13 Taniyama D, Taniyama K, Kuraoka K, Zaitsu J, Saito A, Nakatsuka H, Sakamoto N, Sentani K, Oue N and Yasui W: Long-term follow-up study of gastric adenoma; tumor-associated macrophages are associated to carcinoma development in gastric adenoma. Gastric Cancer 20(6): 929-939, 2017. PMID: 28321517. DOI: $10.1007 / \mathrm{s} 10120-017-0713-\mathrm{x}$

14 Rubio CA, Jonasson JG, Nesi G, Mazur J and Olafsdottir E: The size of colon polyps revisited: Intra- and inter-observer variations. Anticancer Res 30(6): 2419-2423, 2010. PMID: 20651402.

15 Rubio CA, Hoog CM, Brostrom O, Gustavsson J, Karlsson M, Moritz P, Stig R, Wikman O, Mattsson L and Palli D: Assessing the size of polyp phantoms in tandem colonoscopies. Anticancer Res 29(5): 1539-1545, 2009. PMID: 19443363.

16 Japanese society for cancer of the colon and rectum. Japanese classification of colorectal carcinoma. 9th edition. Kanehara \& Co., Ltd.: Tokyo, 2018.

17 Bosman FT, Carneiro F, Hruban RH and Theise ND: Who classification of tumours of the digestive system. World Health Organization, 2010

18 Taniyama K, Ishida K, Toda T, Motoshita J, Kuraoka K, Saito A, Tani Y, Uike T, Teramoto S and Koseki M: Tyrosine1248phosphorylated her2 expression and her2 gene amplification in female invasive ductal carcinomas. Breast Cancer 15(3): 231240, 2008. PMID: 18264744. DOI: 10.1007/s 12282-007-0026-8

19 Watanabe K, Sogawa M, Yamagami H, Watanabe J, Ajioka Y and Arakawa T: Endoscopic differential diagnosis between ulcerative colitis-associated neoplasia and sporadic neoplasia in surveillance colonoscopy using narrow band imaging. Dig Endosc 23(Suppl 1): 143-149), 2011. PMID: 21535221. DOI: 10.1111/j.1443-1661.2011.01135.x
20 Cooks T, Pateras IS, Jenkins LM, Patel KM, Robles AI, Morris J, Forshew T, Appella E, Gorgoulis VG and Harris CC: Mutant p53 cancers reprogram macrophages to tumor supporting macrophages via exosomal mir-1246. Nat Commun 9(1): 771, 2018. PMID: 29472616. DOI: 10.1038/s41467-018-03224-w

21 Yasui W, Kuniyasu H, Yokozaki H, Semba S, Shimamoto F and Tahara E: Expression of cyclin e in colorectal adenomas and adenocarcinomas: Correlation with expression of ki-67 antigen and p53 protein. Virchows Arch 429(1): 13-19, 1996. PMID: 8865848 .

22 Komohara Y, Horlad H, Ohnishi K, Fujiwara Y, Bai B, Nakagawa T, Suzu S, Nakamura H, Kuratsu J and Takeya M: Importance of direct macrophage-tumor cell interaction on progression of human glioma. Cancer Sci 103(12): 2165-2172, 2012. PMID: 22957741. DOI: 10.1111/cas.12015

23 Miyasato Y, Shiota T, Ohnishi K, Pan C, Yano H, Horlad H, Yamamoto Y, Yamamoto-Ibusuki M, Iwase H, Takeya M and Komohara Y: High density of cd204-positive macrophages predicts worse clinical prognosis in patients with breast cancer. Cancer Sci 108(8): 1693-1700, 2017. PMID: 28574667. DOI: $10.1111 /$ cas.13287

24 Edin S, Wikberg ML, Dahlin AM, Rutegard J, Oberg A, Oldenborg PA and Palmqvist R: The distribution of macrophages with a $\mathrm{m} 1$ or $\mathrm{m} 2$ phenotype in relation to prognosis and the molecular characteristics of colorectal cancer. PLoS One 7(10): e47045, 2012. PMID: 23077543. DOI: 10.1371/journal. pone. 0047045

25 Edin S, Wikberg ML, Oldenborg PA and Palmqvist R: Macrophages: Good guys in colorectal cancer. Oncoimmunology 2(2): e23038, 2013. PMID: 23524684. DOI: 10.4161/onci.23038

26 Kang JC, Chen JS, Lee CH, Chang JJ and Shieh YS: Intratumoral macrophage counts correlate with tumor progression in colorectal cancer. J Surg Oncol 102(3): 242-248, 2010. PMID: 20740582. DOI: 10.1002/jso.21617

27 Tanaka M, Kuraoka K, Sakane J, Kodama Y, Nishimura T, Tanaka M, Tatsushima J, Saitou A and Taniyama K: Autoanalysis of immunohistochemical findings for breast cancer using specified software and virtual microscopy. Rinsho Byori 60(3): 206-211, 2012. PMID: 22568082.

28 Komohara Y, Niino D, Ohnishi K, Ohshima K and Takeya M: Role of tumor-associated macrophages in hematological malignancies. Pathol Int 65(4): 170-176, 2015. PMID: 25707506. DOI: 10.1111/pin.12259

29 Saito Y, Komohara Y, Niino D, Horlad H, Ohnishi K, Takeya H, Kawaguchi H, Shimizu H, Ohshima K and Takeya M: Role of cd204-positive tumor-associated macrophages in adult t-cell leukemia/lymphoma. J Clin Exp Hematop 54(1): 59-65, 2014. PMID: 24942947. 